\title{
Textural Evolution by Multiple Steps of Marforming in Ti-Rich Ni-Ti Shape Memory Alloy
}

\author{
A. S. Paula, K. K. Mahesh ${ }^{1}$ and F. M. Braz Fernandes ${ }^{\mathrm{a}, 1}$ \\ CSN - GGDP/GPD, Rod. BR 393, km 5001 - Lúcio Meira, s/n - Vila Santa Cecília - Volta Redonda - RJ - \\ Brazil - CEP 27260-390 \\ UNIFoa - Centro Universitário de Volta Redonda, Campus Três Poços - Av. Paulo Erlei Alves Abrantes, 1325, \\ Três Poços - Volta Redonda - RJ - Brazil - CEP 27240-560 \\ ${ }^{1}$ CENIMAT - I3N, Campus da FCT/UNL, 2829-516 Monte de Caparica, Portugal
}

\begin{abstract}
The Nickel-Titanium (Ni-Ti) alloys are the most attractive amongst shape memory alloys (SMA) due to their good functionality properties coupled with high strength and good ductility. The transformation temperatures in Ti-rich NiTi SMA can be altered with suitable thermal and/or mechanical treatments to obtain martensitic transformation in one or more steps above $0^{\circ} \mathrm{C}$. The goal of the present work is to investigate the textural evolution in Ti-Rich Ni-Ti SMA (Ni-51at\%Ti) that will contribute to different phase transformation sequences (one, two and multiple steps) after being subjected to (i) two distinct thermal treatments $\left(500{ }^{\circ} \mathrm{C}\right.$ for 30 minutes in air and $800^{\circ} \mathrm{C}$ for 300 minutes in vacuum), (ii) followed by multiple steps of marforming ( $30 \%$ thickness reduction by cold rolling), intercalated with thermal treatment at $500^{\circ} \mathrm{C}$ for 30 minutes in air and (iii) four distinct final thermal treatments $(400$, 450,500 or $600^{\circ} \mathrm{C}$ for 30 minutes in air). The textural results were obtained by X-Ray Diffraction (XRD) at room temperature (B19' phase) and at $150^{\circ} \mathrm{C}$ (B2 phase). Differential Scanning Calorimetry (DSC), Electrical Resistivity (ER) and X-Ray Diffraction (XRD) were used to identify the transformation temperatures and the phases that are present after all steps of thermomechanical treatments.
\end{abstract}

\section{Introduction}

In most of the polycrystalline materials, crystal orientations are present in a definite pattern and a propensity for this occurrence is initially caused during crystallisation from the melt or amorphous solid state and subsequently by thermomechanical processes. This tendency is known as preferred orientation or, more concisely, the texture. Many material properties (Young's modulus, Poisson's ratio, strength, ductility, toughness, electrical conductivity etc.) depend on the average texture of a material.

The transformation temperatures in Ti-rich NiTi SMA can be altered with thermal [3,4] and/or mechanical [5,6] treatments adequate to obtain martensitic transformation in one or more steps above $0^{\circ} \mathrm{C}[1,2]$. Heat treatment can promote the nucleation and growth of $\mathrm{Ti}_{2} \mathrm{Ni}$ precipitates. $\mathrm{Ti}_{2} \mathrm{Ni}$ precipitates can disturb or impede the growth of martensite plates [7].

Several studies are dedicated to understand the influence of the texture on thermomechanical response of the SMAs [8-17]. Thermal cycling and mechanical working are found to develop specific texture in metals and alloys. They result in different anisotropy characteristics (mechanical, electrical and magnetic behaviour). NiTi SMAs are also sensitive to these effects. The texture is found to give rise to anisotropy in transformation recovery strain [10]. NiTi SMA in austenitic field has a bcc type texture [13,14]: $\alpha$-fiber I $<110>\|$ RD $(\{001\}<110>-\{112\}<110>-\{111\}<110>), \alpha$-fiber II $<110>\| \operatorname{RD}(\{111\}<110>-\{110\}<110>), \gamma$ fiber $<111>\| \mathrm{ND}$ $(\{111\}<110>-\{111\}<112>)$, and $\eta$-fiber $<100>\| \operatorname{RD} \quad(\{001\}<100>-\{011\}<100>)$. The calculated lattice correspondence between parent phase and martensite using the notation of the correspondence variant from Miyazaki, where $\{110\}<110>$ parent phase variant corresponds to $\{111\}<211>$ and $\{002\}<002>$ martensite variants; and $\{111\}<110>$ parent phase corresponds to $\{210\}<211>$ and $\{210\}<002>[8]$.

In the present work, we have investigated how the multiple steps of marforming thermomechanical treatment in Ni-Ti SMA can affect the final crystallographic texture.

${ }^{a}$ e-mail: fbfefct.unl.pt noncommercial medium, provided the original work is properly cited. 


\section{Materials and Methods}

The samples for the present study were extracted from straight annealed Ti-rich NiTi alloy (Ni-51.0at $\% \mathrm{Ti}$ ) plate of thickness $2 \mathrm{~mm}$ supplied by Memory-Metalle GmbH, Germany. The as-received (AR) samples were subjected to the series of the following thermal/mechanical processes. Initially, the separate samples were subjected to two distinct thermal treatments $\left(500^{\circ} \mathrm{C}\right.$ for 30 minutes in air and $800^{\circ} \mathrm{C}$ for 30 minutes in vacuum, HTA and HTV, respectively), followed by multiple steps of marforming ( $30 \%$ thickness reduction by cold rolling), intercalated with thermal treatment at $500^{\circ} \mathrm{C}$ for 30 minutes in air. Finally, all the samples were thermally treated at four distinct temperatures $\left(400,450,500\right.$ and $600^{\circ} \mathrm{C}$ for 30 minutes in air). The HTV was performed by heating the specimen at the rate of $3^{\circ} \mathrm{C} / \mathrm{s}$, holding at $800^{\circ} \mathrm{C}$ for 30 minutes and subsequently cooling at the rate of $3^{\circ} \mathrm{C} / \mathrm{s}$ up to $\mathrm{T}_{\text {room}}$. The samples were subjected to chemical etching $\left(10 \%\right.$ vol $\mathrm{HF}+45 \%$ vol $\mathrm{HNO}_{3}+45 \%$ vol $\left.\mathrm{H}_{2} \mathrm{O}\right)$, in order to remove the oxide layer, as well as the layer deformed during the cutting operation.

Samples with a mass ranging from 40 to $50 \mathrm{mg}$ were cut from all specimens for DSC analysis (SETARAM DSC92). The following thermal cycle was used for the DSC tests: start temperature at $\mathrm{T}_{\text {room, }}$ heating to $180^{\circ} \mathrm{C}$, holding for $360 \mathrm{~s}$ and subsequent cooling down to $-30^{\circ} \mathrm{C}$, with heating and cooling rates of $7.5^{\circ} \mathrm{C} / \mathrm{min}$.

ER characterisation has been performed by using the home made four-probe set up, which was immersed together with the sample in a silicone oil bath with a temperature control system. It consists of a block of 4 copper rods with wedge-shaped tips. The position of the rods, as well as the pressure that they exert on the test specimen, is individually controlled. A controllable power supply is used to apply the current (1660 mA) into the test specimen. Data acquisition board (National Instruments, USA) with a precision better than $1 \mu \mathrm{V}$ was used to obtain the signal and to interface with a PC. Samples were scanned in the temperature range from -20 to $150^{\circ} \mathrm{C}$.

XRD analysis was performed using a Bruker diffractometer (rotating anode $-\mathrm{XM} 18 \mathrm{H}, \mathrm{CuK} \alpha$ radiation, $30 \mathrm{kV} / 100 \mathrm{~mA}$, D5000 goniometer) with texture analysis at $\mathrm{T}_{\text {room }}$ (B19' phase) and $180^{\circ} \mathrm{C}$ (B2 phase). The rolling direction (RD) was kept aligned in $\varphi=0^{\circ}$ and the transversal direction (TD) in $\varphi=90^{\circ}$.

\section{Results and Discussion}

Figs. 1, 2, and Table 1 show the evolution of the transformation temperatures and the transformation sequence, respectively, for the separate samples undergone HTA and HTV followed by four steps of marforming + thermal treatments. Figs. 1a \& $2 \mathrm{a}$ and Figs. $1 \mathrm{~b} \& 2 \mathrm{~b}$ represent the data of the specimens initially subjected to HTA and HTV, respectively.
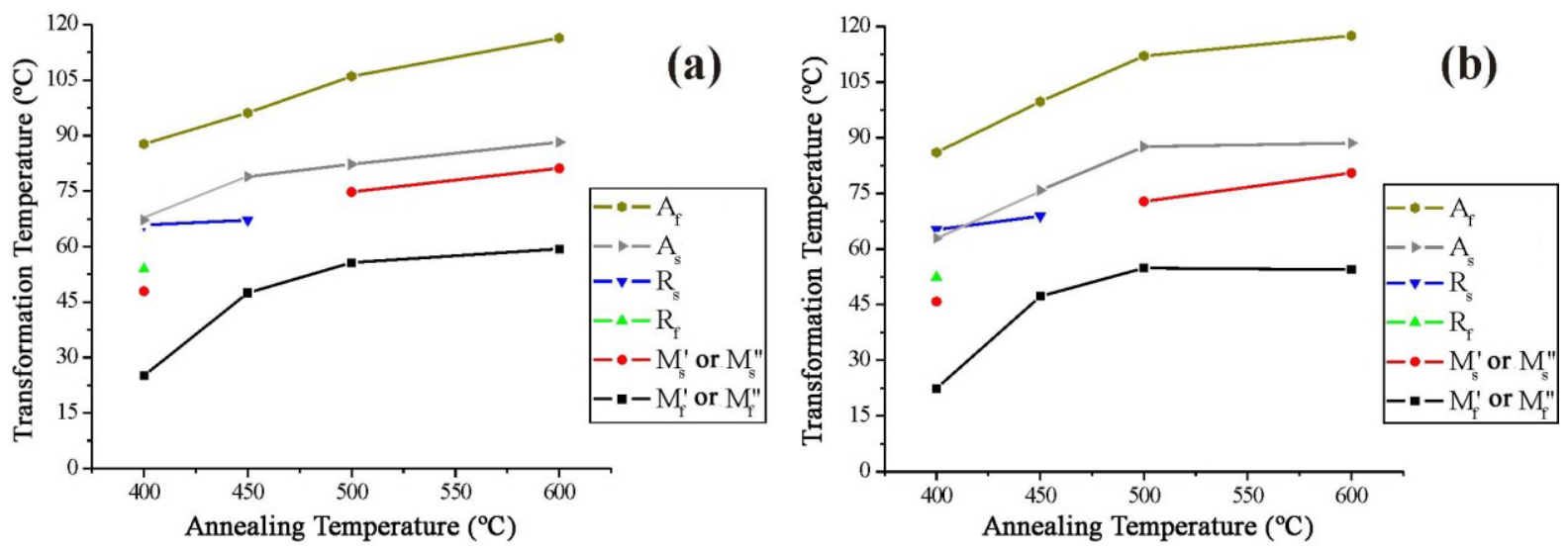

Fig. 1. Evolution of transformation temperatures, extracted from DSC curves of the specimens after thermal $/$ mechanical (multiple steps of marforming) treatments: (a) HTA, and (b) HTV.

Based on the DSC (Fig. 1) and ER (Fig. 2) results, independent from the initial thermal treatments (HTA and HTV), it is observed that in both the cases, there is a clear tendency for the increase of the transformation temperatures of $B 19^{\prime}\left(M_{s}^{\prime} \& M_{f}^{\prime}\left(B 2 \rightarrow B 19^{\prime}\right)\right.$, or $\left.M_{s}^{\prime \prime} \& M_{f}^{\prime \prime}\left(R \rightarrow B 19^{\prime}\right)\right)$ and $B 2\left(A_{s} \& A_{f}\right.$ $\left(\mathrm{B} 19^{\prime} \rightarrow \mathrm{B} 2\right)$ ) phases with increasing annealing temperatures during the final thermal treatments. R-phase transformation occurs for the samples annealed up to $450^{\circ} \mathrm{C}$, during the final thermal treatments. For the sample thermal treated at $400^{\circ} \mathrm{C}$, there exist a clear separation between the transformation temperatures of $B 2 \rightarrow R\left(R_{s}\right.$ and $R_{f}$ ) and $R \rightarrow B 19$ ' $\left(M_{s}\right.$ "' and $\left.M_{f}^{\prime \prime}\right)$. In the present set of study of the samples subjected to series of thermal/mechanical treatments, with respect to the observed phase transformation steps, there can be three distinct behaviour subgroups [18-21]. For the final thermal treatment temperature at $400^{\circ} \mathrm{C}$ the highly deformed 
structure partially recrystallise, giving rise to a two-steps transformation on cooling: $\mathrm{B} 2 \rightarrow \mathrm{R}$ and $\mathrm{R} \rightarrow \mathrm{B} 19^{\prime}$. On heating, the transformation apparently occurs by one step $\left(\mathrm{B}_{19}{ }^{\prime} \rightarrow \mathrm{B} 2\right)$.

Table 1. Transformation Temperatures and Sequences extracted from DSC and ER results.

\begin{tabular}{|c|c|c|c|c|c|c|c|c|}
\hline \multirow{4}{*}{ Samples Conditions } & \multicolumn{8}{|c|}{ Transformation Temperature $\left({ }^{\circ} \mathrm{C}\right)$} \\
\hline & \multicolumn{6}{|c|}{ On cooling } & \multirow{2}{*}{\multicolumn{2}{|c|}{$\begin{array}{l}\text { On heating } \\
\text { B19' } \rightarrow \text { B2 }\end{array}$}} \\
\hline & \multicolumn{2}{|c|}{$\mathrm{B} 2 \rightarrow \mathrm{R}$} & \multicolumn{2}{|c|}{$\mathrm{R} \rightarrow \mathrm{B} 19$} & \multicolumn{2}{|c|}{$\mathrm{B} 2 \rightarrow \mathrm{B} 19^{\prime}$} & & \\
\hline & $\mathrm{R}_{\mathrm{s}}$ & $\mathrm{R}_{\mathrm{f}}$ & $\mathrm{M}_{\mathrm{s}} "$ & $M_{\mathrm{f}}^{\prime \prime}$ & $\mathrm{M}_{\mathrm{s}}^{\prime}$ & $\mathrm{M}_{\mathrm{f}}^{\prime}$ & $\mathrm{A}_{\mathrm{s}}{ }^{\prime}$ & $A_{f}^{\prime}$ \\
\hline HTA+TMT400 & 65,8 & 53,9 & 47,9 & 25,1 & - & - & 66,7 & 87,7 \\
\hline HTV+TMT400 & 65,2 & 52,4 & 45,9 & 22,4 & - & - & 63,1 & 86,0 \\
\hline HTA+TMT450 & 67,1 & $*$ & $*$ & $*$ & $*$ & 47,5 & 78,9 & 96,1 \\
\hline HTV+TMT450 & 68,9 & * & * & $*$ & $*$ & 47,3 & 75,9 & 99,7 \\
\hline HTA+TMT500 & - & - & - & - & 74,8 & 55,6 & 82,2 & 106,0 \\
\hline HTV+TMT500 & - & - & - & - & 72,8 & 54,9 & 87,6 & 112,0 \\
\hline HTA+TMT600 & - & - & - & - & 81,2 & 59,4 & 88,2 & 116,4 \\
\hline HTV+TMT600 & - & - & - & - & 80,5 & 54,4 & 88,6 & 117,5 \\
\hline
\end{tabular}
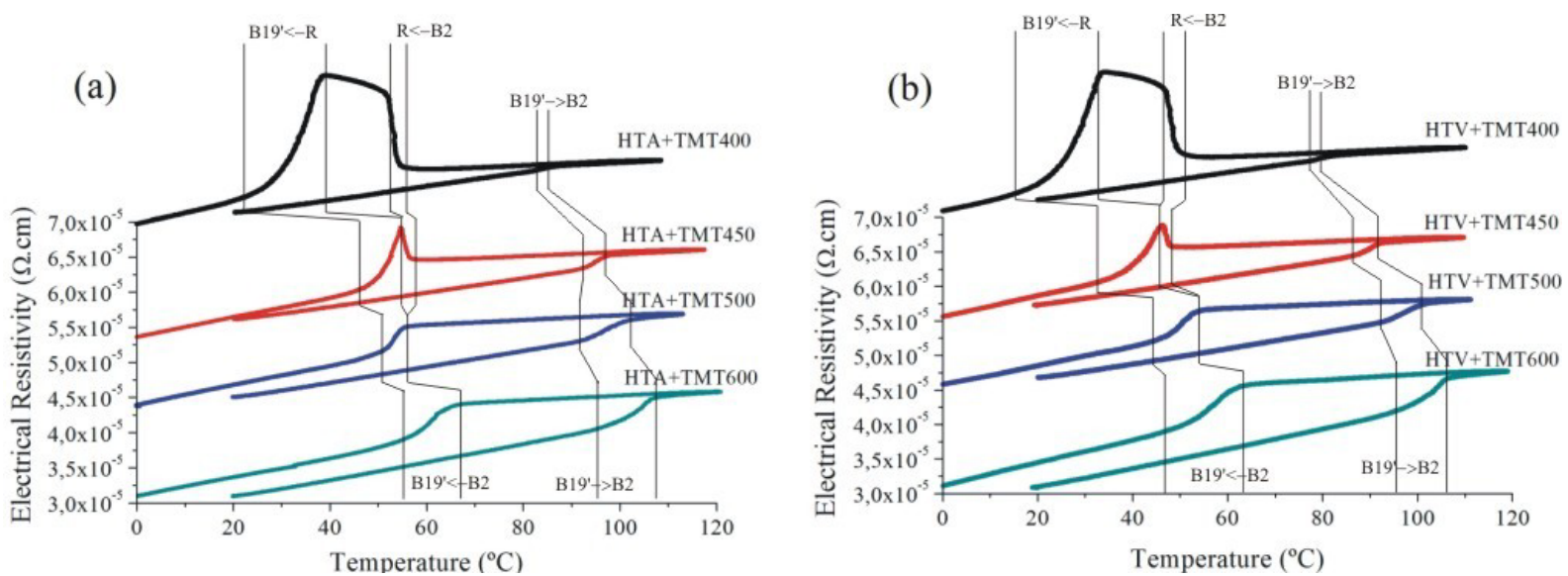

Fig. 2. Evolution of sequence transformation and transformation temperatures represented by ER curves of the specimens after thermal/mechanical (multiples steps of marforming) treatments: (a) HTA, and (b) HTV.

Figs. 3, 4, 5 and 6 show the texture results for the thermal/mechanically treated samples (multiple steps of marforming + thermal treatments) with final thermal treatments at $400,450,500$ and $600^{\circ} \mathrm{C}$, respectively.

Figs. $3 \mathrm{a}, \mathrm{b}, 4 \mathrm{a}, \mathrm{b}, 5 \mathrm{a}, \mathrm{b}$ and $6 \mathrm{a}, \mathrm{b}$ show the pole figures $(11 \overline{1})_{\mathrm{B} 19}$, for the thermal/mechanically treated samples with final thermal treatment at $400,450,500$ and $600^{\circ} \mathrm{C}$, respectively. It is possible to identify the samples which have undergone similar thermal treatments (HTA or HTV) during the first stage. It is observed that the specimens subjected to similar thermal treatments have the same texture components. The reinforcements increase with increasing thermal treatment temperatures. Further, for both sample groups (HTA+TMT and HTV+TMT), a crescent increase in the central texture component contribution in parallel with a decrease of the texture components close to $\chi=45^{\circ}$ shows a trend to increase with increasing annealing temperature. In the martensitic state, the central reinforcements are associated to the $1:(11 \overline{1})[2 \overline{1} 1]_{\mathrm{B} 19}$, and $4:(11 \overline{1})[\overline{2} 1 \overline{1}]_{\mathrm{B} 19}$, texture variants related to $\{110\}<110>_{\mathrm{B} 2}$ and the reinforcement close to $\chi=45^{\circ}$ are associated to the $2:(10 \overline{2})[211]_{\mathrm{B} 19}, 4:(10 \overline{2})[\overline{2} 1 \overline{1}]_{\mathrm{B} 19}$, and $6:(10 \overline{2})[0 \overline{2} 0]_{\mathrm{B} 19}$, texture variants related to $\{111\}<110>_{\mathrm{B} 2}$, that are more intense in the sample group HTA+TMT [19-21].

Figs. 3c,d, 4c,d, 5c,d and $6 \mathrm{c}, \mathrm{d}$ show the pole figures $(110)_{\mathrm{B} 2}$ for the thermal/mechanically treated samples with final thermal treatment at $400,450,500$ and $600^{\circ} \mathrm{C}$, respectively. In the austenitic state, central reinforcements are associated to the $(110)[110]_{\mathrm{B} 2}$ texture component. However, the reinforcement close to $\chi=45^{\circ}$ is associated to the $\{001\}<110\rangle_{\mathrm{B} 2}$ texture components only present in the sample group HTA+TMT and in the condition HTV+TMT600. In the sample group HTV+TMT, with the final thermal treatment above $600^{\circ} \mathrm{C}$, the reinforcement close to $\chi=45^{\circ}$ is associated to the $\{111\}<110>_{\mathrm{B} 2}$ texture components [19-21]. 


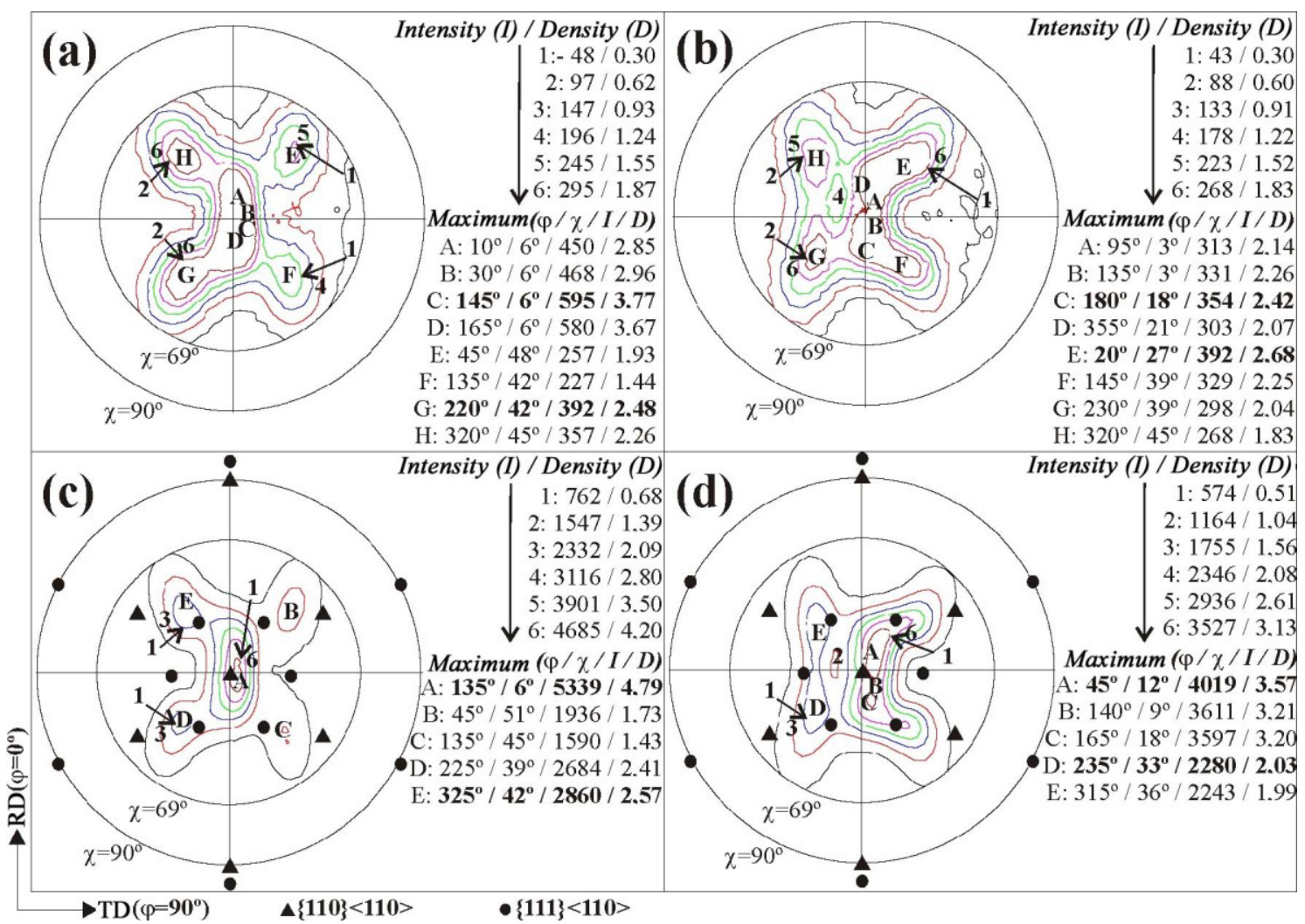

Fig. 3. Pole Figures $(\mathrm{a}, \mathrm{b})(11 \overline{1})_{\mathrm{B} 19}$, and $(\mathrm{c}, \mathrm{d})(110)_{\mathrm{B} 2}$ for the thermal/mechanically treated samples (multiple steps of marforming) with final thermal treatment at $400^{\circ} \mathrm{C}$ samples and previous thermal treatment: (a,c) HTA; (b,d) HTV.

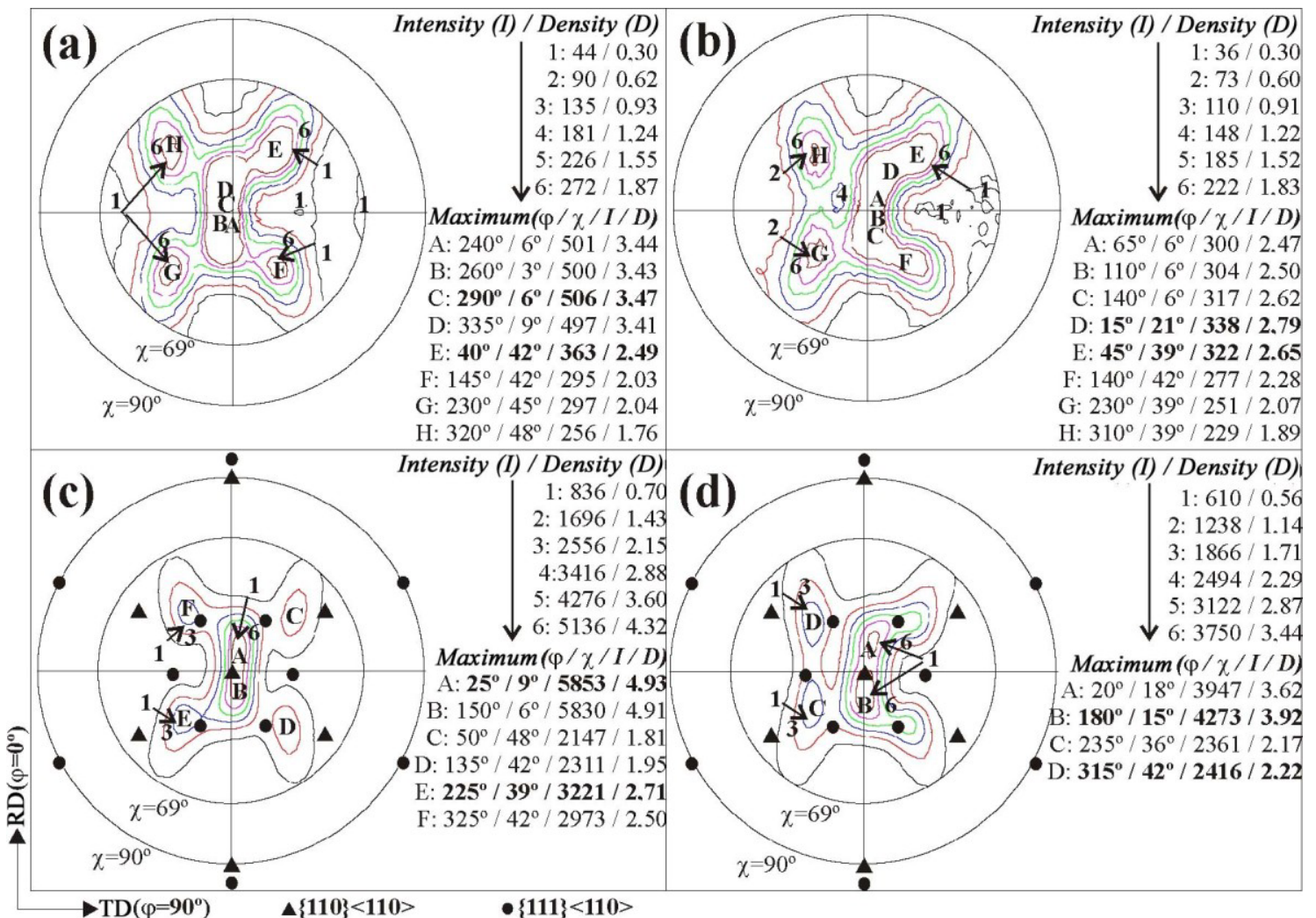

Fig. 4. Pole Figures $(\mathrm{a}, \mathrm{b})(11 \overline{1})_{\mathrm{B} 19}$, and $(\mathrm{c}, \mathrm{d})(110)_{\mathrm{B} 2}$ for the thermal/mechanically treated samples (multiple steps of marforming) with final thermal treatment at $450^{\circ} \mathrm{C}$ samples and previous thermal treatment: (a,c) HTA; (b,d) HTV . 


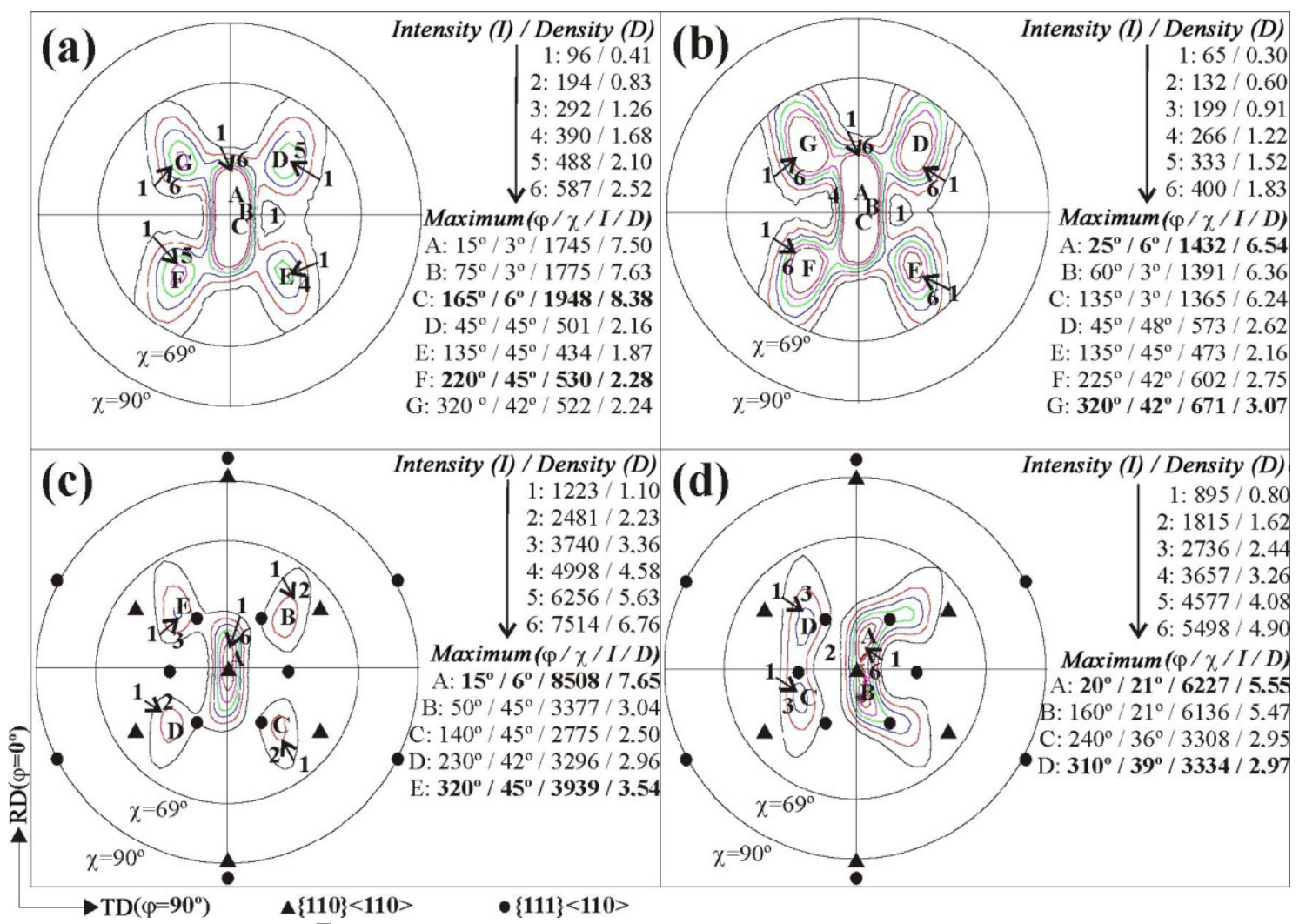

Fig. 5. Pole Figures $(\mathrm{a}, \mathrm{b})(11 \overline{1})_{\mathrm{B} 19}$, and $(\mathrm{c}, \mathrm{d})(110)_{\mathrm{B} 2}$ for the thermal/mechanically treated samples (multiple steps of marforming) with final thermal treatment at $500^{\circ} \mathrm{C}$ samples and previous thermal treatment: (a,c) HTA; (b,d) HTV.

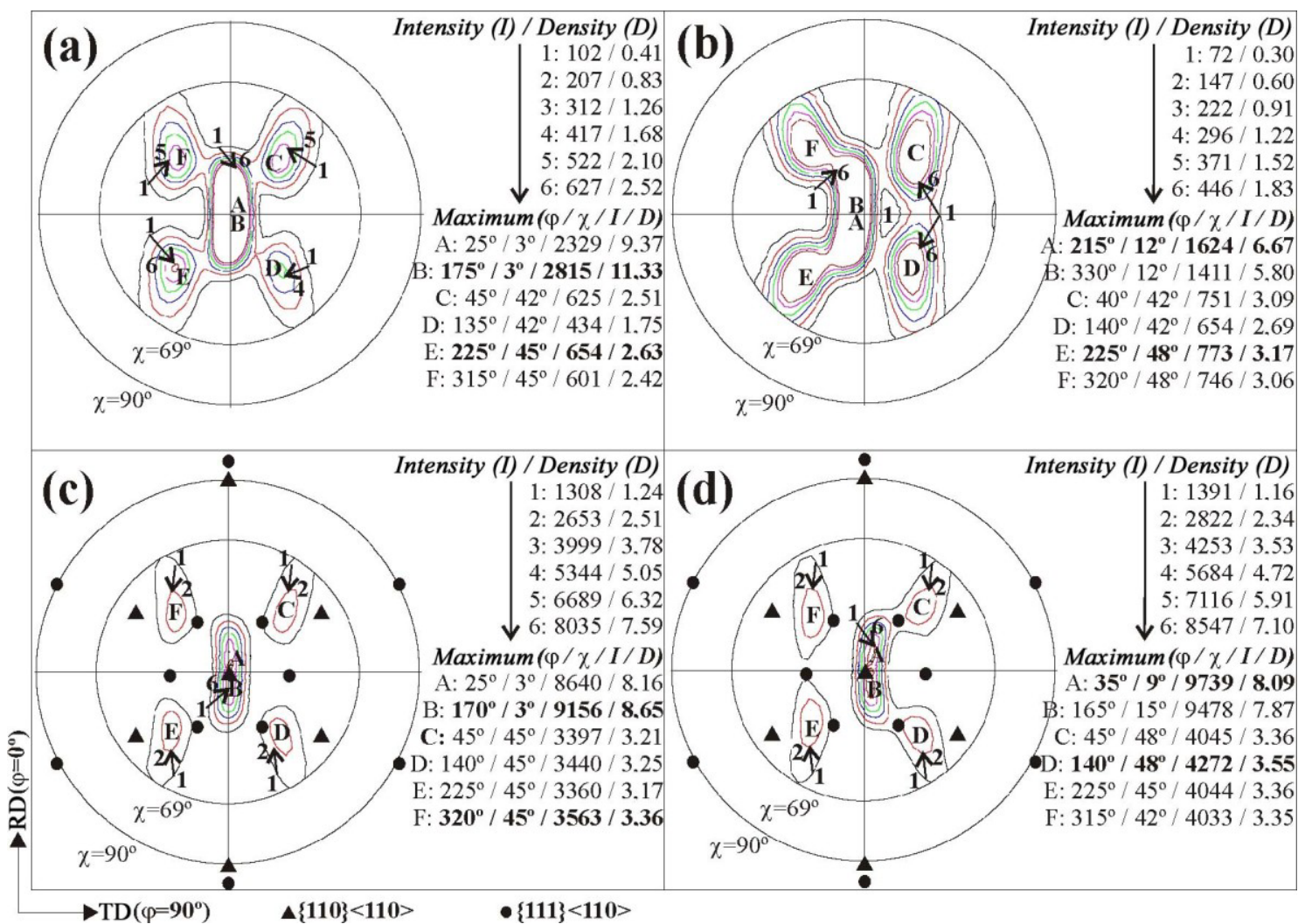

Fig. 6. Pole Figures $(\mathrm{a}, \mathrm{b})(11 \overline{1})_{\mathrm{B} 19}$, and $(\mathrm{c}, \mathrm{d})(110)_{\mathrm{B} 2}$ for the thermal/mechanically treated samples (multiple steps of marforming) with final thermal treatment at $600^{\circ} \mathrm{C}$ samples and previous thermal treatment: (a,c) HTA; (b,d) HTV. 


\section{Conclusions}

After the initial thermal treatments followed by multiple steps of marforming + thermal treatments for the Ti-rich Ni-Ti SMA, it was possible to obtain:

- three groups of phase transformation sequences with respective finish transformation temperatures (for martensitic and austenitic transformations): (i) $\mathrm{B} 2 \rightarrow \mathrm{R} \rightarrow \mathrm{B} 19^{\prime}$ and $\mathrm{B} 19^{\prime} \rightarrow \mathrm{B} 2$ for the samples with the final thermal treatment at $400^{\circ} \mathrm{C}$ (HTA+TMT400 and HTV+TMT400); (ii) B2 $\rightarrow \mathrm{R}, \mathrm{B} 2 \rightarrow \mathrm{B} 19^{\prime}, \mathrm{R} \rightarrow \mathrm{B} 19^{\prime}$ and $\mathrm{B} 19^{\prime} \rightarrow \mathrm{B} 2$ for the samples with the final thermal treatment at $450^{\circ} \mathrm{C}$ (HTA+TMT450 and HTV+TMT450); and (iii) $\mathrm{B} 2 \leftrightarrow \mathrm{B} 19^{\prime}$ for the samples with the final thermal treatment above $500^{\circ} \mathrm{C}$ (HTA+TMT500, HTA+TMT600, HTV+TMT500 and HTV+TMT600);

- a maximization of the central reinforcement intensity close to the $(110)[110]_{\mathrm{B} 2}$ and a decrease of the secondary reinforcement intensity close to the components associated to $\{001\}<110>_{\mathrm{B} 2}$, in other words, a mixture of $\alpha$-II and $\alpha$-I fibers.

The authors acknowledge FCT/MCTES for the pluriannual financial support of CENIMAT/I3N.

\section{References}

[1] A.L. McKelvey, R.O. Ritchie, Metal. Mat. Trans. 32A, 731 (2001).

[2] K.N. Melton, O. Mercier, Acta Metal. 29, 393 (1981).

[3] A.S. Paula, J.P.H.G. Canejo, R.J.C. Silva, F.M. Braz Fernandes, Mat. Sci. Forum II 455-456, 346 (2004).

[4] A.S. Paula, J.P.H.G. Canejo, R.M.S. Martins, F.M. Braz Fernandes, Mat. Sci. and Eng. A378, 92 (2004).

[5] S.K. Wu, H.C. Lin, P.C. Cheng, J. Mat. Sci. 34, 5669 (1999).

[6] S.K. Wu, H.C. Lin, Y.C. Yen, J.C. Chen, Mat. Lett. 46, 175 (2000).

[7] J.X. Zhang, M. Sato, A. Ishida, Acta Mater. 51, 3121 (2003).

[8] S. Miyazaki, K.Otsuka, C.M.Wayman, Acta Metall. 37, 1873 (1989).

[9] L. Zhao, Texture Development and Anisotropic Behaviour in a Ti-45Ni-5Cu (at.\%) Shape Memory Alloy, Ph.D. thesis, University of Twente, Enschede, The Netherlands (1997).

[10] K. Kitamura, S. Miyazaki, H. Iwai e M. Kohl, SMST-97: Proceedings of the Second International Conference on Shape Memory and Superelastic Technologies, Pacific Grove, CA - USA, March 2-6, 1997, edited by (ASM International, 1997), p. 47.

[11] A.S. Paula, J.P.H.G. Canejo, N. Schell, F.M. Braz Fernandes, NIM-B 238, 111 (2005).

[12] F.M. Braz Fernandes, A.S. Paula, J. Canejo, K.K. Mahesh, R.J.C. Silva, R.M.S. Martins, A.M.A. Cardoso, N. Schell, Texture Evolution During Annealing of Ni-Ti Shape Memory Alloy, SMST 2004: Proceedings of the International Conference on Shape Memory and Superelastic Technology, Baden-Baden, Germany, October 3-7, 2004, edited by Matthias Mertmann (ASM International, 2004), p. 45.

[13] T. Bhattacharya, R.V. Kohn, Acta Mater. 44, 529 (1996).

[14] Y.C. Shu, K. Bhattacharya, Acta Mater. 46, 5457 (1998).

[15] A.S. Paula, J.H.P.G. Canejo, K.K. Mahesh, R.J.C. Silva, F.M. Braz Fernandes, R.M.S. Martins, A.M.A. Cardoso, N. Schell, NIM-B 246, 206 (2006).

[16] A.S. Paula, K.K. Mahesh, F.M. Braz Fernandes, R.M.S. Martins, A.M.A. Cardoso, N. Schell, Mat. Sci. Forum 495-497, 125(2005).

[17] A.S. Paula, C.M.L. dos Santos, J.P.H.G. Canejo, K.K. Mahesh, F.M. Braz Fernandes, C.S. da Costa Viana, Textural Evolution in Ti-rich and Ni-rich Ni-Ti Shape Memory Alloys Submitted to Thermomechanical Treatment with Marforming Steps, ABM2007: 62th Annual ABM Congress - Vitória-ES / Brazil (ABM, 2007), p. 3426.

[18] E. Hornbogen, Mater. Sci. Forum 455-456, 335 (2004).

[19] A.S. Paula, J.P.H.G. Canejo, R.M.S. Martins, F.M. Braz Fernandes, Mat. Sci. and Eng. A378, 92(2004).

[20] F.M. Braz Fernandes, A.S. Paula, J. Canejo, K.K. Mahesh, R.J.C. Silva, Texture Evolution During Annealing of Ni-Ti Shape Memory Alloy, SMST 2004: Proceedings of the International Conference on Shape Memory and Superelastic Technology, Baden-Baden, Germany, October 3-7, 2004, edited by Matthias Mertmann (ASM International, 2004), p. 51.

[21] A.S. Paula, Tratamentos termomecânicos de ligas do sistema Ni-Ti. Caracterização estrutural e optimização das propriedades associadas ao efeito de memória de forma, PhD Thesis, FCT/UNL, Lisbon - Portugal (2006). 